\title{
A Study of Blockage Effects at the Wind Turbine and Wind Farm Scales
}

\author{
Mihaela Popescu ${ }^{1}$ and Tore Flåtten ${ }^{2, *}$
}

check for

updates

Citation: Popescu, M.; Flåtten, T. A Study of Blockage Effects at the Wind Turbine and Wind Farm Scales. Energies 2021, 14, 6124. https:// doi.org/10.3390/en14196124

Academic Editor: Davide Astolfi

Received: 14 August 2021

Accepted: 13 September 2021

Published: 26 September 2021

Publisher's Note: MDPI stays neutral with regard to jurisdictional claims in published maps and institutional affiliations.

Copyright: (c) 2021 by the authors. Licensee MDPI, Basel, Switzerland. This article is an open access article distributed under the terms and conditions of the Creative Commons Attribution (CC BY) license (https:/ / creativecommons.org/licenses/by/ $4.0 /)$.
1 Analitics \& Digital, Department of Resource Assessment, Methods and Tool Team, RWE Renewables UK, Swindon SN5 6PB, UK; mihaela.popescu@rwe.com

2 Department of Energy and Petroleum Engineering, University of Stavanger (UiS), 4036 Stavanger, Norway

* Correspondence: tore.h.flatten@uis.no; Tel.: +(47)-51-83-00-00

\begin{abstract}
The paper provides novel insights into the physics behind the wind turbine and wind farm blockages as well as their effects on the energy yield based on the momentum and energy balance. The current work presents blockage effects at two scales: the local scale and the wind farm scale. We clarify the combined effect of local blockages when more than one turbine is present. The work demonstrates why two turbines, which are positioned one behind the other, induce a mutual decrease in energy yield. When the turbines are placed in a row, there is an increase of energy from the end to the middle of the row because of the restriction of the expansion flow. As in the case of two turbines placed behind each other, back rows induce a power decrease for the rows in front of them and the effect increases from the edge to the center. The work also elucidates for the first time how the power output of an isolated row has a maximum in the center, whereas, in a wind farm, wind turbines on the edge of the first row could have maximum power. The findings are supported by CFD.
\end{abstract}

Keywords: blockage effect; wind farms; blockage interaction; induction; CFD

\section{Introduction}

Currently, wind energy plays an important role in sustainable and green energy supply. The evolution of the wind industry has been remarkable, and in the last four decades, much progress has been made in installations, technology advancements, and cost reductions. The global share of wind power production is targeted at 35\% globally by 2050 for the G20 countries, five of them targeting over $40 \%$ [1].

Since the cost of wind energy is expected to continue to reduce, it will be a core technology in achieving decarbonization. "Wind energy will become the no. 1 source of electricity in Europe shortly after 2025 and by 2030 it will provide 25\% of the EU's electricity needs" [2].

The blockage effect is an important phenomenon that needs to be understood and evaluated to be able to have a good prediction of wind farm production. It is a consequence of two-way interaction between wind turbines and wind flow. It influences the energy production of the wind turbine and the fatigue of the blades.

As wind approaches an obstacle, it will be slowed down and diverted. This is known as one of the blockage effects. In recent years, it has become increasingly clear that an improved understanding of the interaction between structures and various blockage effects is needed for a better prediction of wind farm energy yields. Usually, the engineering models, such as the Jensen or Ainslie wake model [3], do not include the wind farm blockage effect. In this case, the engineering models provide a good approximation for not too large wind farms. However, they have difficulty in modeling large wind farms, or clusters of wind farms, where blockage effects can become more complex and noticeable. As an alternative to correct this problem, WindFarmer [4], a software tool, has introduced an artificial correction for large offshore wind farms. 
Presently, there are attempts to incorporate the blockage effect in the engineering models. The four models reviewed by Branlard et al. [5] consider the blockage effect through modeling the speed from the induction zone. Segalini [6] creates a new model that includes the blockage effect, which is based on the linearized RANS equation. Nygaard et al. [7] present two new models for wind turbine interaction effects and a recipe for combining them: the Optimized Park model and a full engineering wind farm blockage model. The authors signaled the idea that a better model could not be created without an understanding of the relevant physics behind blockage effects.

For turbines placed in a single row perpendicular to the wind direction, there is a side effect indicated by McTavish et al. [8] through experiments, and Nishino and Draper [9] through CFD simulations. They observe a small positive increase in the power production in the center of a row. Hägglund et al. [10] found for a dense wind farm that the turbines in the middle of the first row have a higher wind speed deficit than turbines located at the edge of the row. These apparently contradictory results will be clarified in this paper.

The work done by Ebenhoch et al. [11] and Segalini and Dahlberg [12] indicate that blockage is a complex phenomenon that can affect wind farm energy production in positive and negative ways. Segalini and Dahlberg [12] showed experimentally that the velocity in the front row depends on the layout: the number of rows and spacing between the first row and the rest of the wind farm. They proved that the first line is not affected only by the flow perpendicular to it, but also by the presence of the downstream turbine. This was shown by using a farm consisting of 100 wind turbines, in which the distance between the first row and the rest of the wind farm was variable. Comparing the maximum and minimum distance in their experiment, they observed a velocity difference of $2 \%$ in the first row.

The previous works indicate the two important facts that affect the blockage effect in a wind farm. First, that the lateral wind turbine could introduce a beneficial effect in a row, but also, rows have a negative effect on rows in front of them. The novelty of the current work reveals the physics of the two phenomena. This knowledge is used to emphasize, for the first time, how these two phenomena are accumulated in the wind farm. The cumulative effect could explain, for the first time, the apparent "surprisingly" different behavior of blockage in a row. The blockage could have a negative effect on the first row of the wind farm, but it has a beneficial effect on an isolated row. The physics behind the effects of blockage at the wind farm level is based on the understanding of the effects created by the presence of a single turbine.

The present work, supported by CFD computation and literature studies, aims to reveal the physical reason and the origin of the blockage effects. Section 2 presents general remarks on the blockage effects. Section 3 presents the computational set-up. Section 4 summarizes and analyses the physics behind the blockage effects created by an isolated wind turbine and in the wind farm. This section will target not only the direct blockages, but also the understanding of the physics of indirect effects. They are created by the interaction between direct blockage effects and turbine rotors. The relevant results are discussed in Section 5. Finally, in Section 6, the key findings of the work are summarized.

\section{General Remarks on Blockage}

The blockage effects are the consequence of the presence of the wind turbines on the atmospheric boundary layer and on the other wind turbines. The blockage effect can be considered at three scales:

(1) The individual wind turbine scale (or local scale);

(2) The wind farm scale;

(3) The regional scale.

The first level contains blockage effects that are the consequence of the direct interaction between a single wind turbine and the atmospheric layer. The most evident blockage effects are associated with the induction zone and the wake. The induction zone is caused by the turbine thrust, where the wind decelerates in front of the rotor. The wind speed 
reduction is maximal close to the rotor and negligible from five rotor radii upfront [13]. Other local blockage effects are the expansion flow and the speed increase, for example around the rotor and the wake.

The blockage effects at the level of the wind farms scale are the consequence of the two-way interaction with the atmospheric layer by wind farm turbines. These lead to substantial changes in both, the structure of the atmospheric layer and the energy efficiency of the farm. As at the wind turbine scale, the most evident blockage effects at the wind farm scale are induction zones, wake in the wind farm, and a change of harvested power.

The third blockage scale is the regional scale, which is created by wind farms and their interaction between the flow dynamics of wind farms in the same cluster, modifying the atmospheric layer. There are two types of regional blockage effects. The first blockage effect is the modification of the atmospheric boundary layer as the result of its direct interaction with the wind farm, leading to a harvest of a part of the atmospheric layer energy by the farm. The second type of blockage effect is the result of the wind farm blockage interaction between farms situated in the same cluster, or sufficiently close to influence each other. Nygard and Hasen [14] indicated that a wind farm can have both positive and negative effects on other wind farms. The accumulation of the induction effect created by a wind farm can be well estimated by a scanning LiDAR [15]. Even though regional blockage effects are important, they are not considered in this paper.

\section{Methods}

The study of the physics behind the blockage effects created by wind turbines and farms is based on CFD computation and experiments found in the literature. Herein, our focus is to obtain a qualitative description of the phenomena of interest.

Most computations were done using OffWindSolver, a wind farm layout design tool, which was developed by SINTEF within the OpenFOAM architecture [16]. The turbine modeling was based on actuator line concepts derived from the SOWFA code, where each blade of the turbine is represented as a line $[17,18]$. The simulations were run on a distributed cluster architecture.

The actuator line model (ALM) replaces the impact of the rotating blades by body forces that are distributed in points along lines representing wind turbine blades directed outwards from the hub. Each point represents a discrete section of the blade. In consequence, a structured grid can be used around the wind turbine, and significantly fewer grid points are necessary to capture the influence of the blades compared to simulations that resolve the flow details around each blade [19].

The local velocity at each ALM element (see Figure 1) is calculated by the solver. The flow produces local forces, lift and drag. These are computed in the center of each segment using tabulated data such as chord, blade airfoil type, twist, and local velocity in the center of each element of the blade [20]:

$$
L=\frac{1}{2} C_{l}(\alpha) \rho u_{r l l}^{2} c w \text { and } D=\frac{1}{2} C_{d}(\alpha) \rho u_{r e l}^{2} c w,
$$

where $C_{l}$ and $C_{d}$ are the lift and drag coefficient respectively for a 2-D airfoil, $c$ is the cord length, $w$ is the actuator width length, $\alpha$ is the angle of attack, and $u_{r e l}$ is the fluid velocity relative to the blade. The normal and tangential forces of each element of the blade are obtained by projecting lift and drag forces to the normal and tangential direction of the rotor. These forces are represented as source terms in the momentum equations, thus enabling the coupling between the flow field and the blades.

The fluid velocity relative to the blade is decomposed into a normal component $U_{n}$ and a tangential component $U_{t}$, which are used together with the twist angle $\beta$ to compute the angle of attack $\alpha$ [20]:

$$
\alpha=\tan ^{-1}\left(\frac{U_{n}}{U_{t}}\right)-\beta,
$$




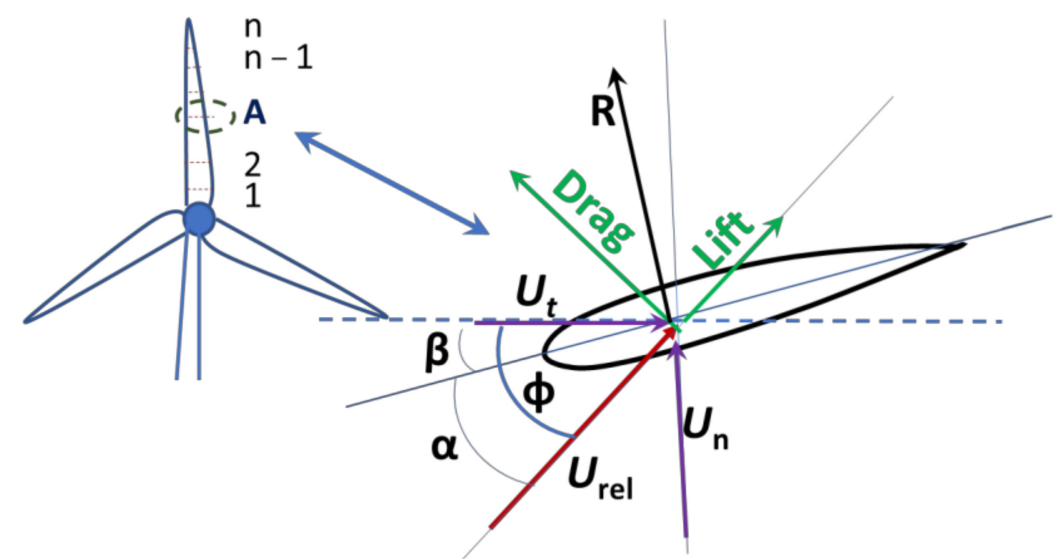

Figure 1. The actuator line force.

If the actuator line forces are applied directly to the flow field at single points, numerical stability issues arise. To avoid this problem, the force is distributed smoothly on several mesh points (Gaussian distribution), which is done by taking the convolution between the force and kernel [17]:

$$
f_{\varepsilon}=f \otimes \eta_{\varepsilon} \text { and } \eta_{\varepsilon}=\frac{1}{\varepsilon^{2} \pi^{2}} \exp \left[-\left(\frac{d}{\varepsilon}\right)^{2}\right],
$$

where $d$ is the distance between the considered point and the actuator line element, and $\varepsilon$ is a parameter that serves to adjust the concentration of the regularized load.

The 3D computation considers the Siemens SWT-2.3-93 wind turbines with hub height equal to $90 \mathrm{~m}$. The solution is obtained using the RANS $\mathrm{k}-\varepsilon$ model and at least 25 grid points on the rotor diameter (see Figure 2). For the flow around one turbine, a finer grid was used to better catch the flow-wind turbine interactions. The computation considers offshore wind conditions, i.e., negligible roughness to the ground and low turbulence, $7 \%$.

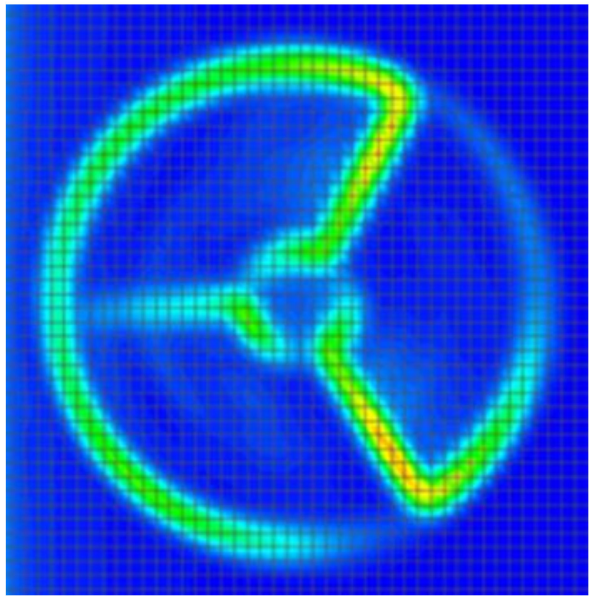

(a)

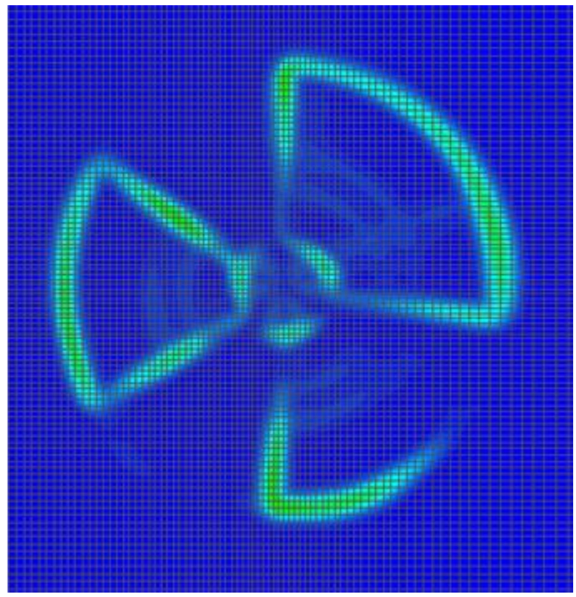

(b)

Figure 2. Mesh used for the flow around a wind turbine- the vorticity is plotted to visualize the rotor and the grid points on it: (a) mesh on the rotor; (b) finer mesh used around a single wind turbine.

The 3D computational domain considers flat terrain, with the following boundary conditions:

- Sides + top: symmetry-normal flux is zero;

- Bottom: wall-no slip;

- Front: inflow/Dirichlet—fixed velocity; 
- Back: outflow/Neumann-zero-gradient;

- The three-dimensional computation considers the buoyancy effect by using an atmospheric solver developed in the SOWFA. The computation is done in a neutral atmospheric stability.

With the use of Fluent 16.1, some qualitative two-dimensional computations were used to highlight the physics of the interaction between blockage effects for a row of wind turbines and between rows. The solution is obtained using the RANS k- $\varepsilon$ model with 24 grid points on the $50 \mathrm{~m}$ porous zone, which plays the role of the rotor. The porous zones do not accurately represent a particular wind turbine.

The computation does not include all of the wind turbine characteristics, but it gives a representation of the flow interactions that create the blockage effects of a wind farm. Consequently, the precise speed variation for an isolated wind turbine can be different than for a real turbine, but the physics are well captured. The inlet wind speed is set to $9 \mathrm{~m} / \mathrm{s}$ and the turbulence is $7 \%$.

The 2D computational domain is equipped with the following boundary conditions:

- Lateral symmetry-normal flux is zero;

- Front: inflow/Dirichlet-fixed velocity;

- Back: outflow/Neumann-zero-gradient.

In the computational domain, the turbines are located 8 or more rotor diameters from the lateral boundaries, at least 6 rotor diameters from the inlet, and at least 8 rotor diameters from the outlet.

\section{Results}

\subsection{The Effect of the Blockage Created by the Presence of an Isolated Wind Turbine}

The presence of a wind turbine affects the wind flow profile both upwind and downwind $[21,22]$. The effects created by a blockage of a wind turbine can be summarized as (see Figures 3 and 4):

- The induction zone, which is the area in front of the wind turbine, where there is a decrease in velocity and an increase in pressure of the wind flow.

- The lateral expansion flows, which are created because of the presence of the wind turbine.

- The increase of the wind flow speed, for example around the rotor and wake. The speed increase and expansion flow are not independent phenomena. They are the consequence of the mass and momentum conservation.

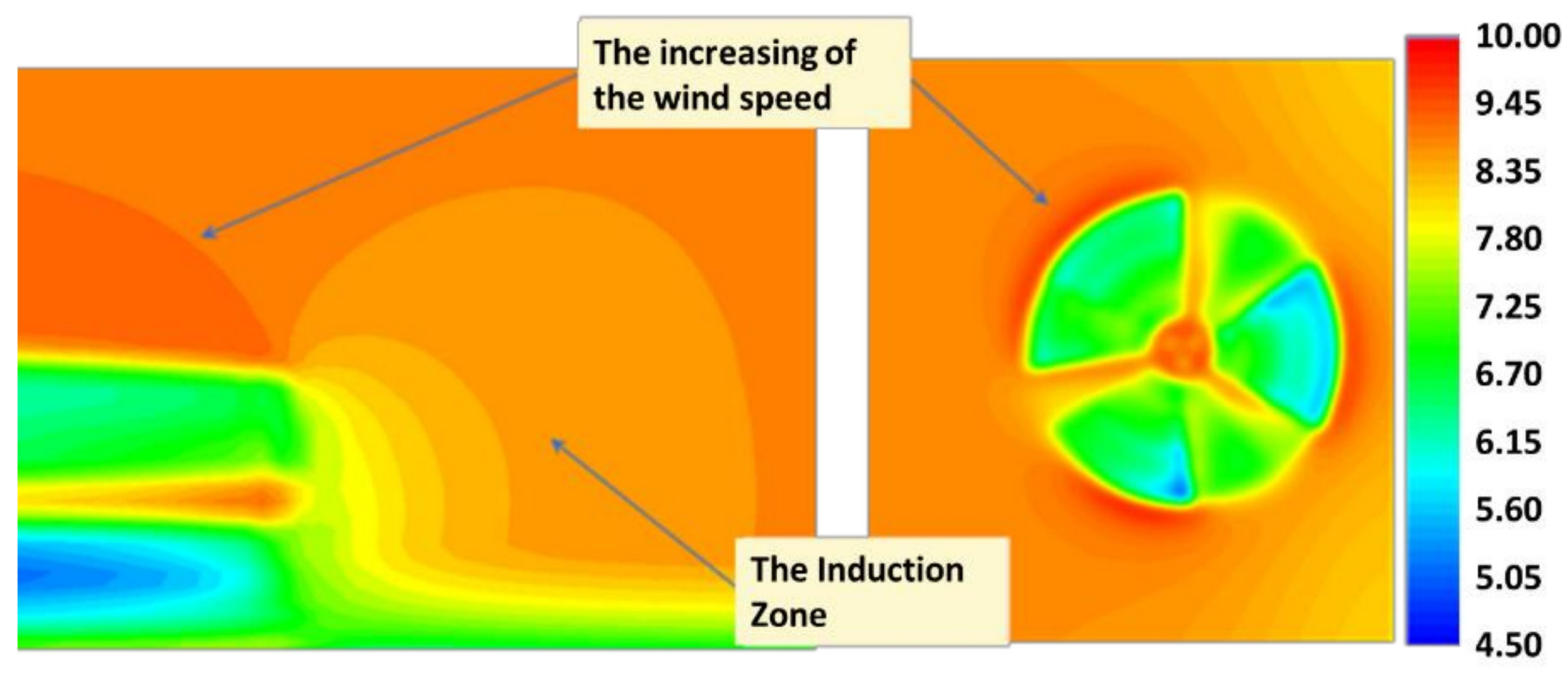

Figure 3. Velocity contour of the flow around one turbine; inlet speed $=9 \mathrm{~m} / \mathrm{s}$. Left: transversal section on the wind turbine, showing the induction zone in the front of the turbine and increasing wind flow around the wake. Right: velocity contours on the wind turbine rotor plane-wind speed increases around the rotor. 


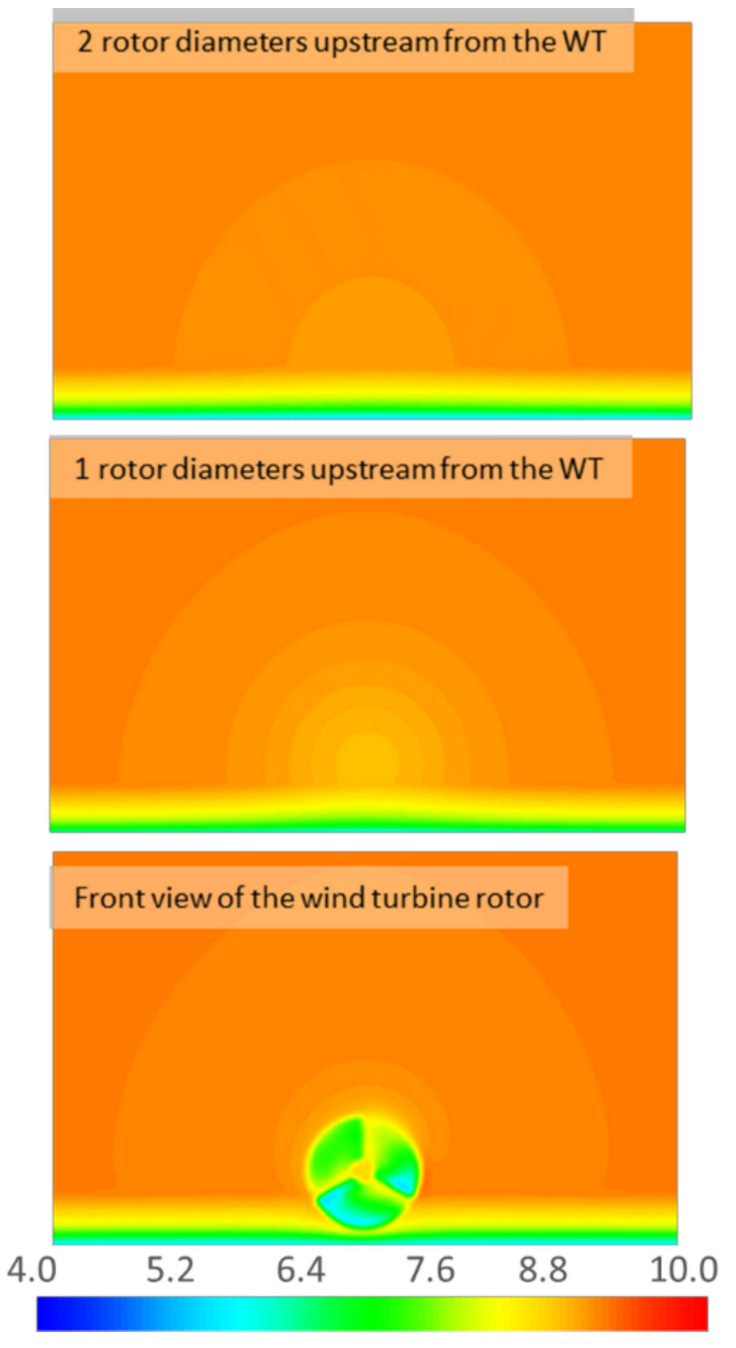

(a)

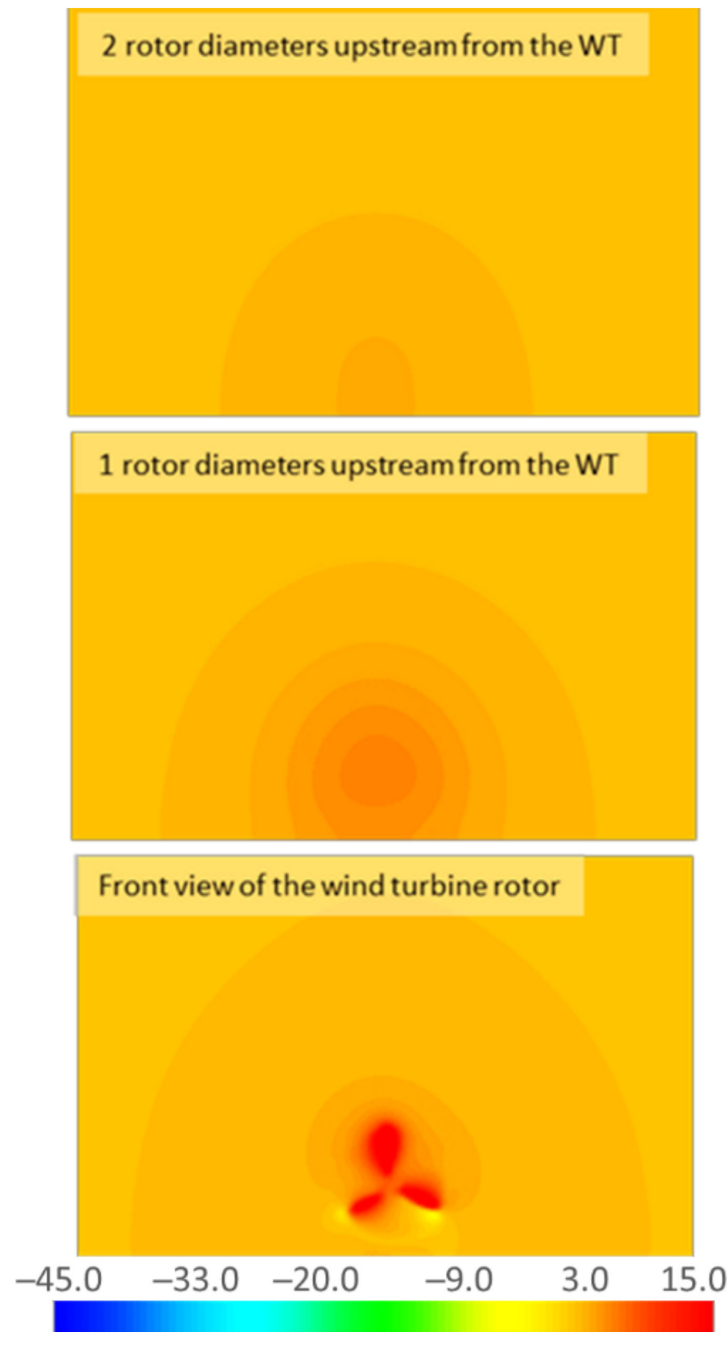

(b)

Figure 4. Upstream wind flow approaching the wind turbine: (a) speed; (b) static pressure.

\subsubsection{The Induction Zone}

The presence of the wind turbine in the atmospheric layer creates an induction zone in front of the turbine, which is a direct effect of the thrust. The wind flow approaching the rotor has an increase in pressure and decrease in speed. The maximum effect is in the front of the rotor, whereas it is negligible a few rotor diameters upfront of the rotor [13]. The strength of the induction is the consequence of the momentum conservation. It depends on the properties of the wind flow and the wind turbine characteristics.

The flow approaching the turbine decelerates (see Figure 4), expands and accelerates around the rotor. The measurements study of Simley et al. [23] indicated that the mean radial wind speeds "increase close to the edge of the rotor disk". How much the flow expands and accelerates around the rotor is a consequence of the energy balance, momentum and mass conservation.

In principle, the wind flow is characterized by two types of energy: potential energy (the pressure head) and kinetic energy (the velocity head). The kinetic energy decreases as the speed decreases because of the turbine thrust. Since no work is done ahead of the wind turbine, and the kinetic energy decreases, the potential energy, which is a direct consequence of pressure head, increases to conserve the total energy-see Figures 4 and 5. 


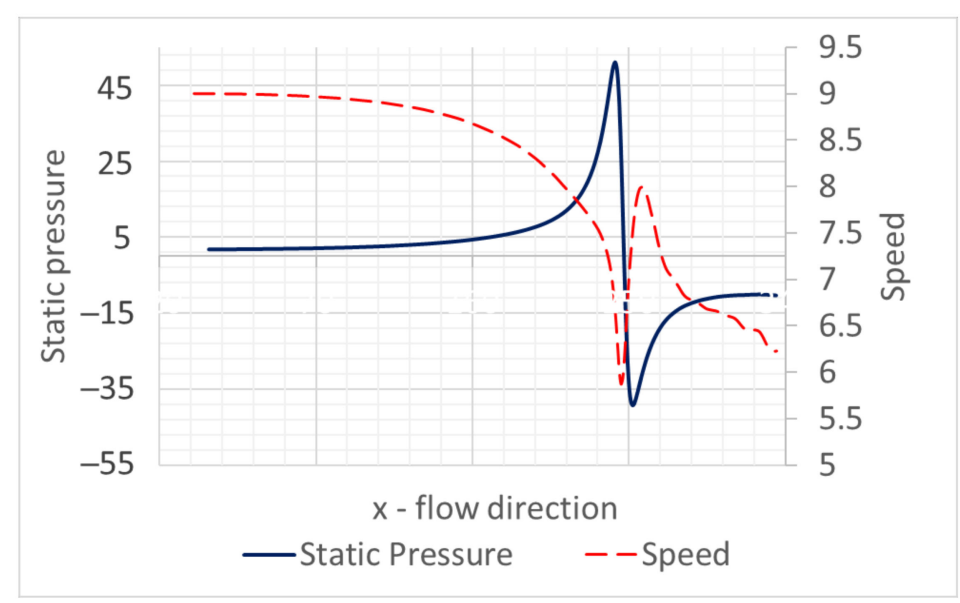

Figure 5. Static pressure and speed around wind turbine rotor on a line across the wind turbine rotor.

Since in the induction zone the pressure increases and kinetic energy decreases, the turbulence level decreases in the axial direction. However, when the flow is approaching the rotor, there is an increase in turbulence level because of the tip vortex effect.

The induction zone was studied by Simley et al. [23] by using LiDAR measurements. The measurements support findings obtained in this paper through CFD: (i) the wind flow has an axial dominant direction; (ii) wind flow approaching the wind turbine rotor has a decreasing axial wind speed component; (iii) the mean radial wind speed around the wind turbine increases due to expansion flow-an increase of around 9\% was noticed at the edge of the rotor disk for high power coefficient; (iv) there is a general decrease in the longitudinal turbulence component. A decrease of up to $22 \%$ of the standard deviation of the estimated freestream value was noticed when the turbine was operating with high power coefficient, around 0.54 .

The flow field and forces related to operating wind turbine rotors are governed by the balance between the thrust and torque on the rotor, and the kinetic energy of the incoming flow field [22].

\subsubsection{Blockage Effect behind a Wind Turbine}

The flow leaving the rotor has a drop of energy since the wind turbine transforms a part of the wind energy into mechanical energy. This generates a drop in the pressure head on the rotor area. The sudden decrease in pressure creates an increase in speed. The suction on the sides of the rotor blade induces a vortex structure.

The flow downstream of the wind turbine has a diminished kinetic energy and an increase in turbulence that is referred as wake.

\subsection{The Blockage Effect at the Wind Farm}

The presence of multiple wind turbines and their two-way interaction with the atmospheric layer flow can lead to substantial changes in both the structure of the atmospheric layer and the capacity to harvest the energy from the wind flow by the turbine. The blockage effects at the wind farm scale are the result of:

- The direct effect of the presence of the turbines.

- Interaction between local blockage effects and other turbine rotors.

- The wind farm induction zone in the front of a row, which is the result of the interference between the individual turbine induction zones.

- An increase of wind speed on the lateral parts of the wind farm and wind turbine lines, because of mass conservation.

The extent and strength of the farm induction zone depend on the wind-farm size, layout, turbulence, wind direction, turbine spacing, and thrust coefficient of the wind turbines. Using both a cylindrical vortex wake model and actuator-disk simulations, 
Branlard [24] shows that at 2.5 rotor diameters in front of a wind farm the wind flow may be reduced by $3 \%$ with respect to the actual incoming flow speed. Bleeg et al. [25] indicate a similar reduction by measurements.

The magnitude of the speed change over a wind farm is determined by the local energy conservation, the mass and momentum conservation and the forces that govern the operation of the wind turbines.

\subsubsection{Blockage Effects Created by Turbines Placed in a Line-One behind the Other}

The blockage effects created in a line of wind turbines situated behind each other can be divided into two types. The first type is the direct interaction between the atmospheric layer and wind turbines, as described in the previous chapter. The second type is the specific two-way interaction between turbines in a line.

The wind farm induction zone is more visible in the front of turbines or rows that are not affected by the wake. Consequently, many studies were focused on such turbines, even induction zones are present in front of all wind farm turbines. The turbulent flow and sometimes well-structured vortices in the wake diminish the blockage effects. Hence a fine resolution is required to be able to notice the induction zones.

Figure 6 depicts the pressure distribution around two turbines placed behind the other, where the second is placed at 4.5 rotor diameters distance behind the first. The picture clearly shows the induction zone for both wind turbines. The pressure increases in the front of the turbines and decreases behind the turbines. A characterization of wind flow in the induction zone and over the rotor for a turbine located in the wake can be revealed by following the variation of pressure and velocity on a line perpendicular to the second wind turbine rotor-see Figure 7. The wind flow around a turbine in the wake has similar aspects as for one in a free wind flow: (i) a reduction of the velocity and a pressure increase in the induction zone; (ii) there is a decrease in pressure and a small increase in speed between wind turbine rotor faces, which is followed by a decrease in speed and pressure increase.

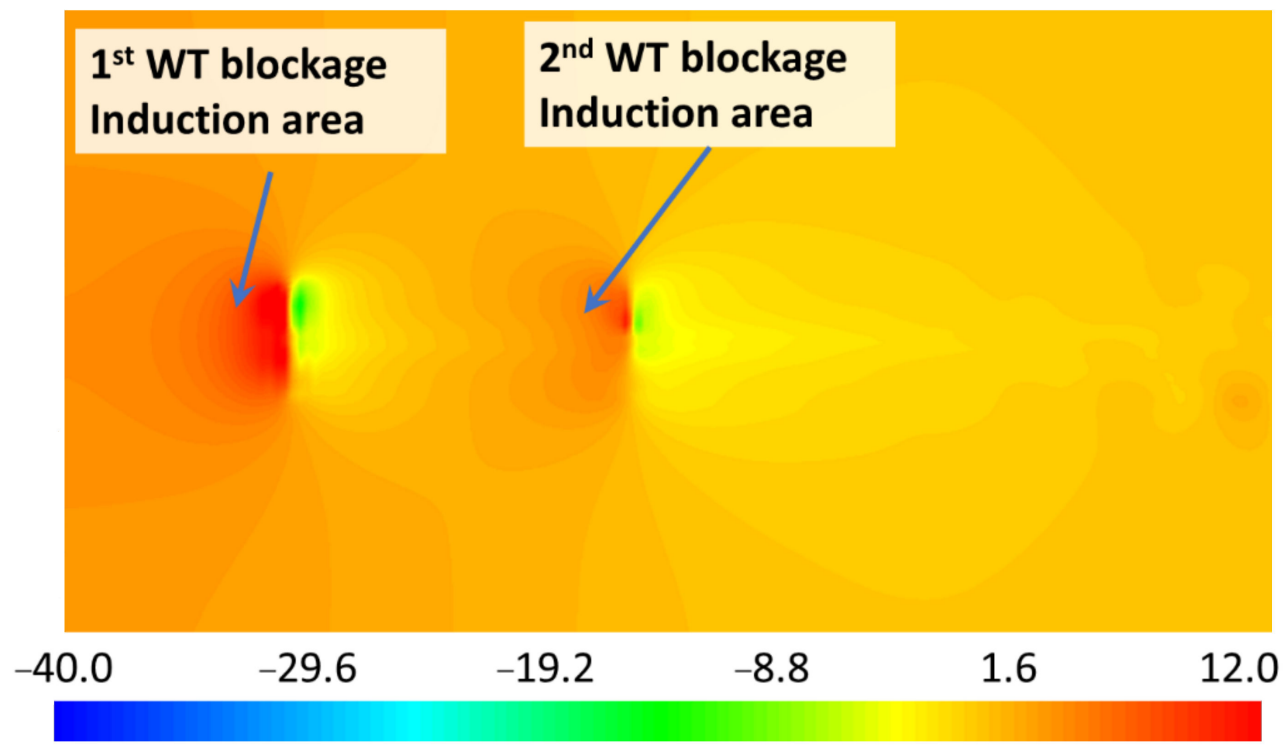

Figure 6. Blockage effects and their interaction: static pressure-two turbines in line 4.5 rotor diameters apart.

There is a two-way interaction between blockage effects of two turbines situated one behind the other. The first, turbine wake affects the energy production of the second turbine, by reducing the speed and increasing the loads because of turbulence. The second wind turbine induction affects the energy production of the first turbine and its induction zone. 


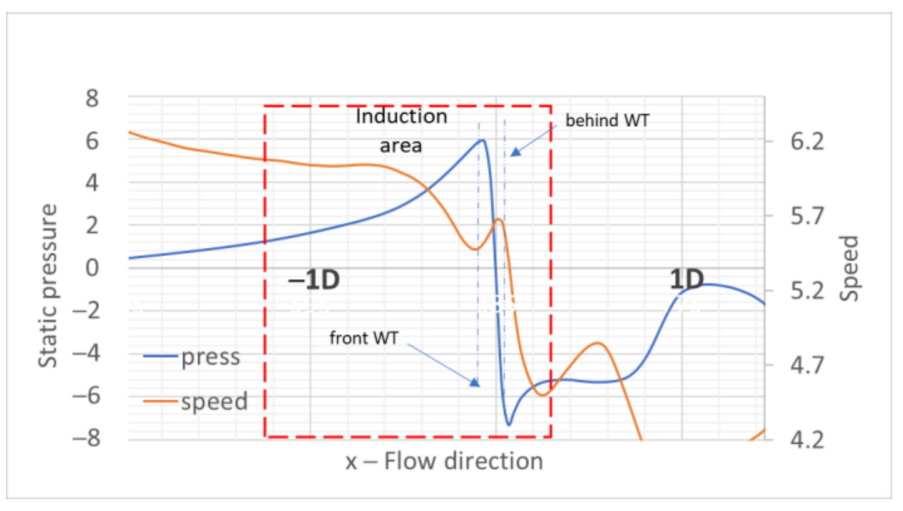

Figure 7. The pressure and speed in the induction zone and over the rotor for the second turbine in line-distance from the first turbine is 4.5 rotor diameters.

The effect of the induction zone of the back turbine on the front turbine can be understood by considering the momentum in the control volume around the front wind turbine [26]:

$$
\frac{\partial[\rho U]}{\partial t}=\frac{\Delta p}{\Delta x_{F}}-\frac{T+\left\langle\tau_{W}\right\rangle}{V_{c v}}-f
$$

where $\rho, u$, and $p$ are the fluid density, streamwise velocity and pressure, $V_{C V}$ is the control volume, $x_{F}$ the streamwise horizontal coordinate, $\tau$ denotes the stress, $T$ is the turbine drag and $f$ is the body force acting in the streamwise direction. The square brackets represent volume-averaging, and $\Delta p$ is the average pressure drop in the streamwise direction across the control volume $(\mathrm{CV})$.

$$
\Delta p=\left\langle p_{\text {in }}\right\rangle-\left\langle p_{\text {out }}\right\rangle,
$$

Because of the presence of the second turbine, there is a decreasing pressure variation over the control volume because of its induction zone, which induces a lowering speed. The induction zone of the second turbine induces a decrease of the kinetic-see Figures 6 and 8 . Consequently, the kinetic energy available for the first wind turbine is reduced because of the presence of the second wind turbine. This has as a direct effect a small reduction of wind speed over the rotor of the wind turbine behind it, which creates a small decrease in power. Figure 8 shows results of 3D CFD computations for two turbines that are placed one behind the other at two different distances apart. The second wind turbine is located at 4.5 and 8 diameters apart, respectively. The pressure and velocity around the first turbine are plotted along a line that is perpendicular to the rotor center. When the distance between the first and second turbine is smaller, there is a higher pressure and reduced speed behind the second turbine. These effects induce a power decrease and a stronger induction zone for the first turbine. This result is consistent with the experimental observations done by Segalini and Dahlberg [12], which indicates that the velocity in the first row of a wind farm depends on rows behind.

Figure 9 shows a well-defined induction zone in front of each turbine, for a line of seven wind turbines at 4.5 diameters distance apart. The weakest induction zone is in the front of turbine four, where there is higher turbulence. This is the place where the tip vortex breaks down-see Figure 10. All the turbines situated in the wake have a small variation of power deficit because of the presence of the wake and the interaction between induction zones and the wind turbines in front-see Figure 11:

- The third turbine reduces the energy harvest by the second turbine. This will increase the kinetic energy available for the third turbine, which then has an induction zone with a higher potential energy.

- The fourth wind turbine will have the same effect on the third turbine, which will slightly reduce the effect of the third on the second turbine, and so on. 


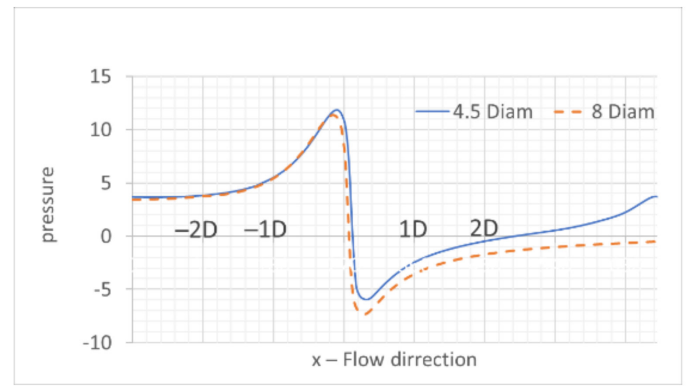

(a)

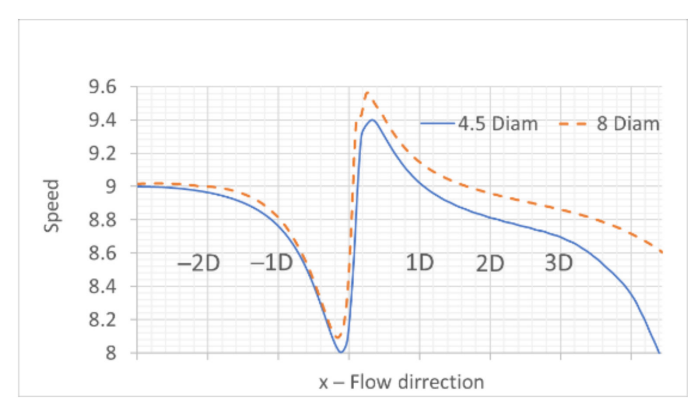

(b)

Figure 8. The pressure and speed profile around first turbines and behind turbines are located at 4.5 respective 8 diameter from the first turbine. The $x$-axis is perpendicular to the center of the rotor of the turbines: (a) pressure; (b) speed.

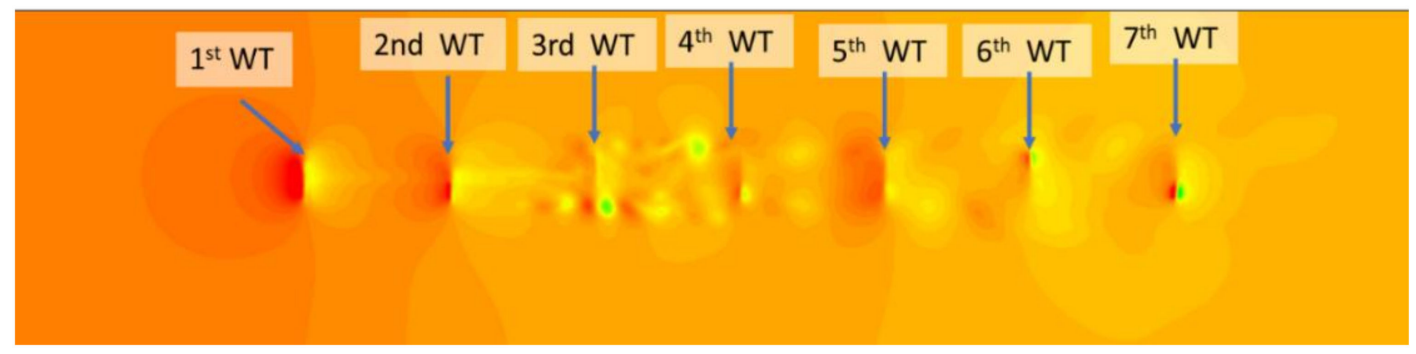

Figure 9. The pressure distribution around a line of wind turbines, with seven turbines at 4.5 diameters distance apart. The induction zone in the front of each turbine is clearly visible.

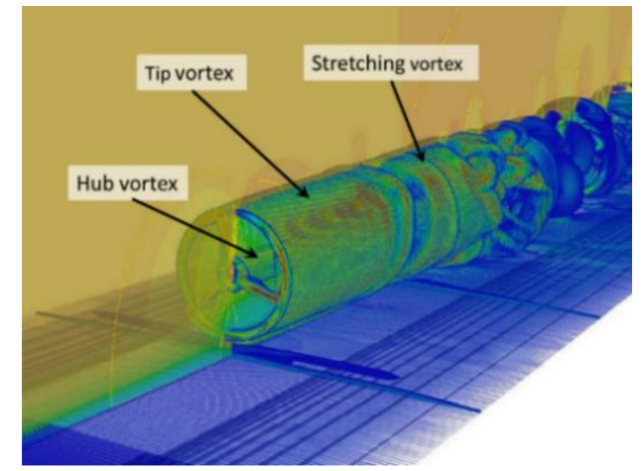

Figure 10. The vortex distribution on a wind turbine line.

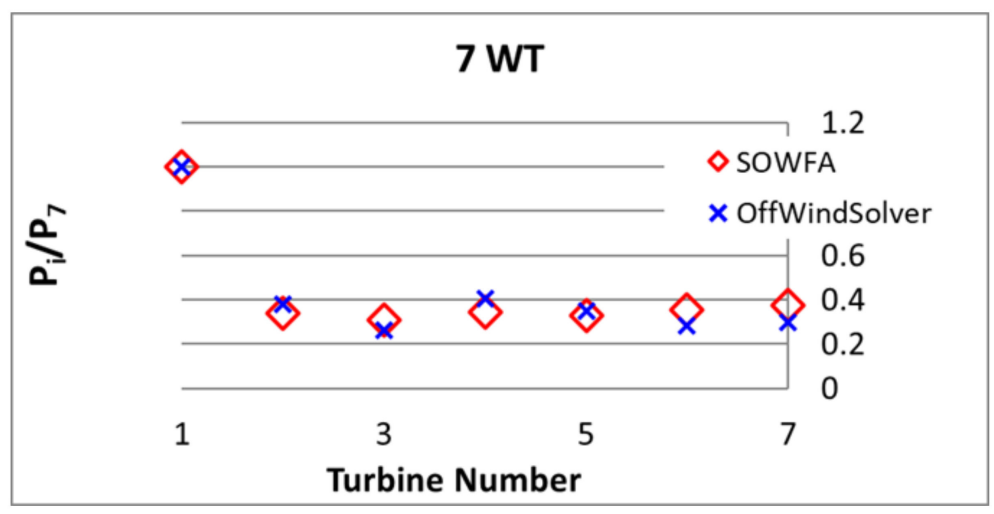

Figure 11. The power ratio between each wind turbine of the line with respect to the first turbine (number 1). 


\subsubsection{The Wind Farm Blockage Effects Created in and by a Turbine Row}

In this chapter, the studied effects consider that the rows and turbine rotors are relatively perpendicular to the wind direction. Through numerical simulations we now aim to elucidate the physics behind the blockage effects arising from:

- The influence of the lateral wind turbines in the row, by using a row with five and seven wind turbines.

- The influence of a wind turbine row to the turbine row in front. The numerical experiment considers two wind turbine rows, the second being behind the first. The second row has: (i) five turbines that are placed directly behind the turbines of the first row; (ii) six turbines that are placed facing the gaps between the turbines of the first row-see Figure 12.

- The influence of the distance between turbines on the strength of the induction zone and power output. The analysis was done using five turbines with a distance varying among two, four, and seven wind turbine rotor diameters.

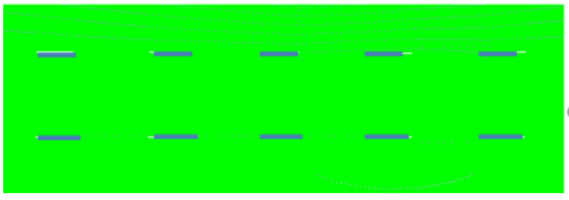

(a)

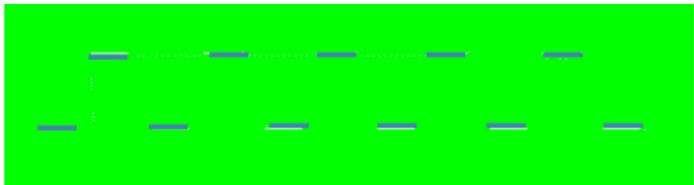

(b)

Figure 12. Two different arrangements of wind turbine rows: (a) 5 turbines that are placed directly behind the turbines of the first row; (b) 6 turbines that are facing the gaps between the turbines of the first row.

Figures 13 and 14 show that the pattern of an induction zone of one turbine is repeated in the front of each turbine in a row. But the induction zones of turbines in the row are not the same and they differ from induction zone of one turbine row. The row has five turbines at three rotor diameters apart. For the isolated turbine, the computation domain was reduced so that the distance to the boundary was the same for the isolated turbine as for the row. Otherwise, the conditions were the same. In a row with multiple turbines, the induction zones have a smaller lateral expansion than one row with a single turbine because they are restricted to a limited area. In the induction zone of the row, the freedom of the turbine expansion flow decreases from edge to center. Hence, and the energy is restricted to a smaller volume for each turbine from edge to center. Consequently, there is a small increase in the induction zone intensity, a tangential speed decrease, and an increase of energy availability from edge to center-see Figures 15 and 16. The harvested energy by turbines increases from edge to center of the row because of the increase of available energy. Hence, the speed over the turbine rotors of the row increases accordingly.

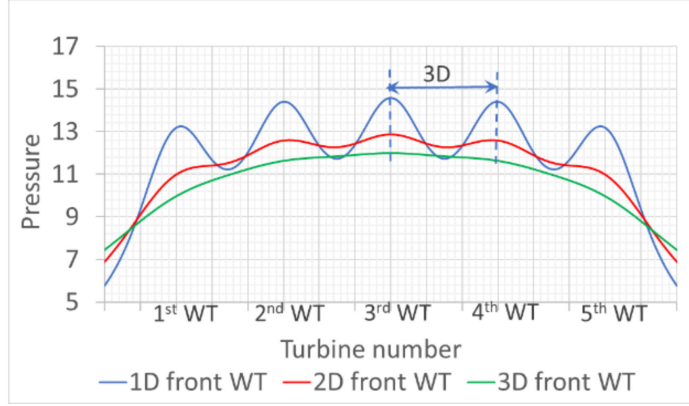

(a)

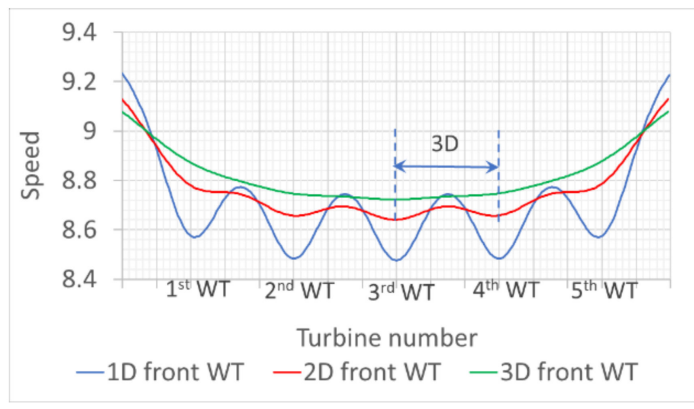

(b)

Figure 13. Induction zone of wind turbine row: (a) static pressure; (b) speed. 


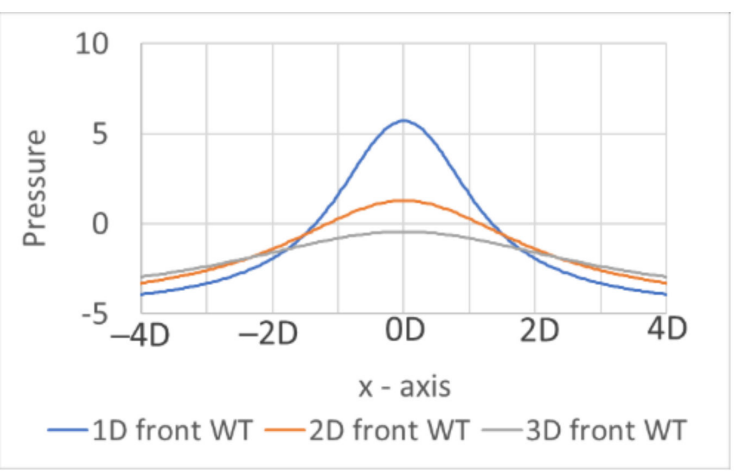

(a)

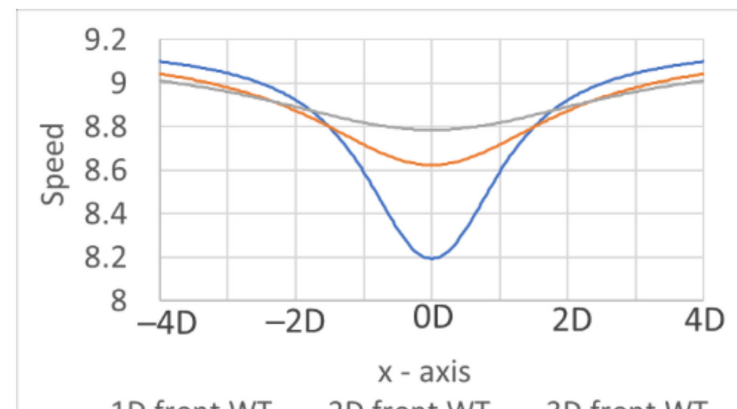

-1D front WT — 2D front WT —3D front WT

Figure 14. Induction zone of only one turbine: (a) static pressure; (b) speed.

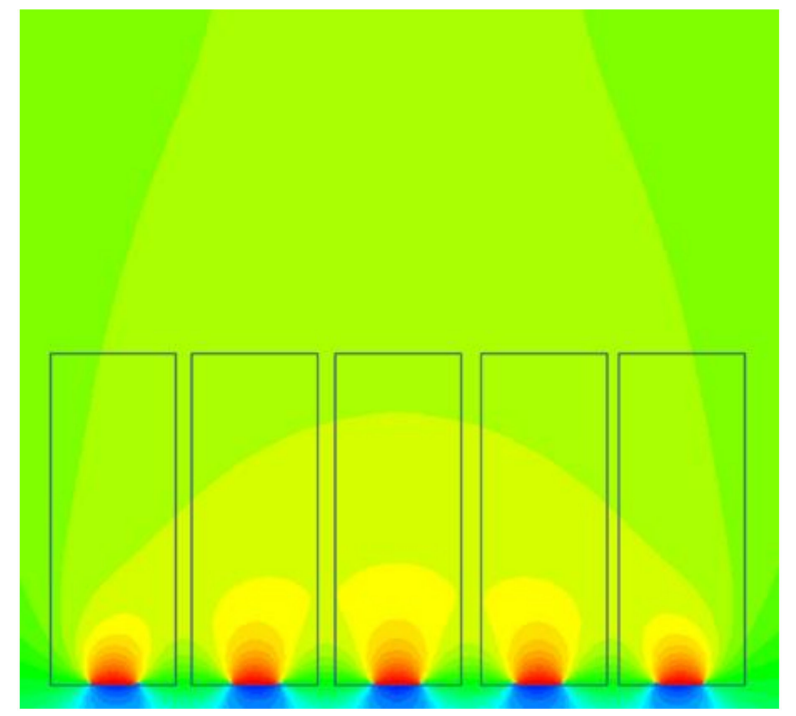

Figure 15. The pressure distribution and control volume around wind turbines from a row.

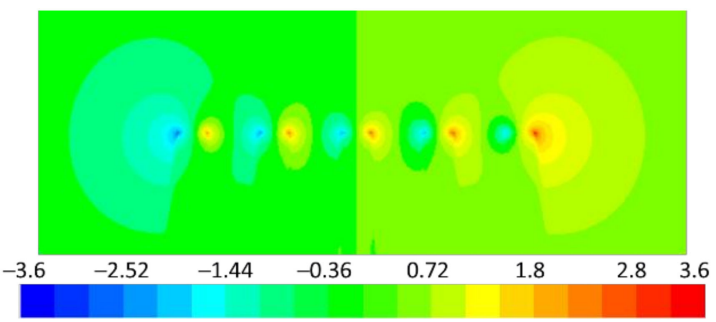

(a)

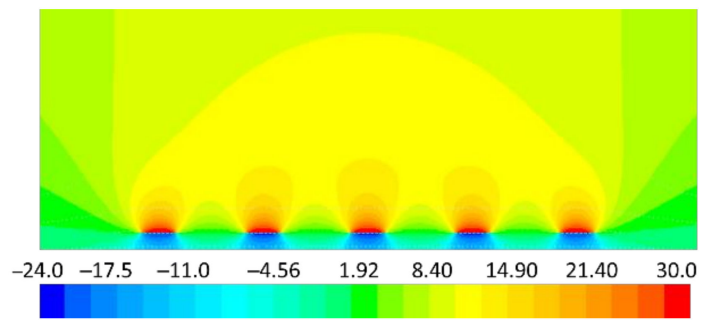

(b)

Figure 16. The contour plot of the flow of a wind turbine row: (a) tangential velocity around turbines; (b) pressure in the induction zone.

By increasing the number of the turbines in a row, the freedom of lateral expansion flow decreases from edge to center. Therefore, adding turbines will cause the total energy in the control volume in front of the row to increase, and the radial speed to decrease. This will induce a larger increase of harvested energy by turbines and speed over the rotors from edge to center-see Figure 17. 


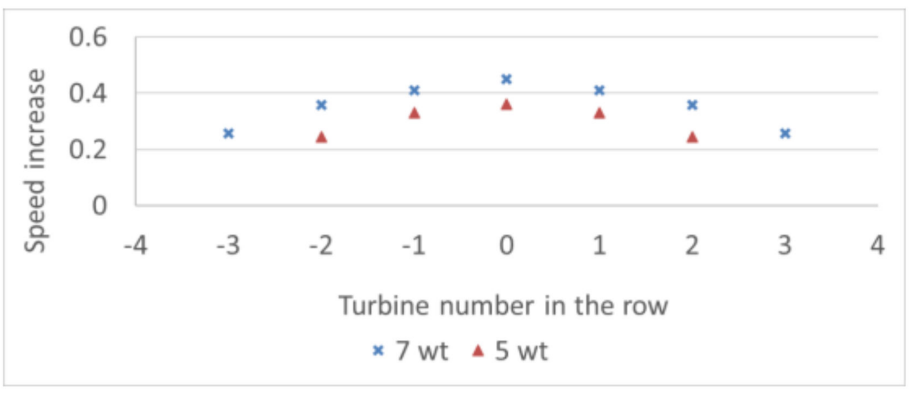

Figure 17. The effect of varying the number of turbines in a row. The percent of the speed increase in front of wind turbine rows compared to a row of one turbine.

The three-dimensional computation conducted by Nishino and Draper [9] indicated similar results: (i) the center turbine of a row has a higher power coefficient than the rest of the row; (ii) the power efficiency of a row increases with the number of turbines in the row. The experiment done by McTavish et al. [8] also found an increased mean power for the wind turbine situated in the center of the row.

By using 3D CFD, Meyer and Troldborg [27] proved that for a wind turbine row with a small distance between turbines (3 rotor diameters) and a strong yaw (larger or equal to $15^{\circ}$ ), the power coefficient increases from left to right while the induction zone strength decreases. The power coefficient increases from a power deficit to a positive power depending on the yaw direction. In this case, a dominant role in the power production is played by the tangential flow created by yaw, which will increase the wind flow from left to right.

The blockage in the row can be expressed in two different ways:

- The power increases from edge to center of the row when all the turbines have the rotor perpendicular or almost perpendicular to the wind direction.

- The power increases from one edge to another, when all the turbine rotors are close and have strong yaw (larger than $15^{\circ}$ ) when there is a strong influence of tangential flow.

The rotor as a porous zone was modeled with a larger pressure jump compared to the previous presented study. Hence, a larger pressure changes over the rotor compared to Figure 17 is created. This induces an increase of the thrust in front, which gives us the possibility to see a stronger effect of the lateral interaction in the induction zone-see Figure 18. By decreasing the distance between turbines, the freedom of lateral expansion decreases, hence an increase of total energy of the induction zone of the row is created. Both the power harvested by the turbines and the speed over the rotors increase accordingly, with a maximum increase in the center of the row.

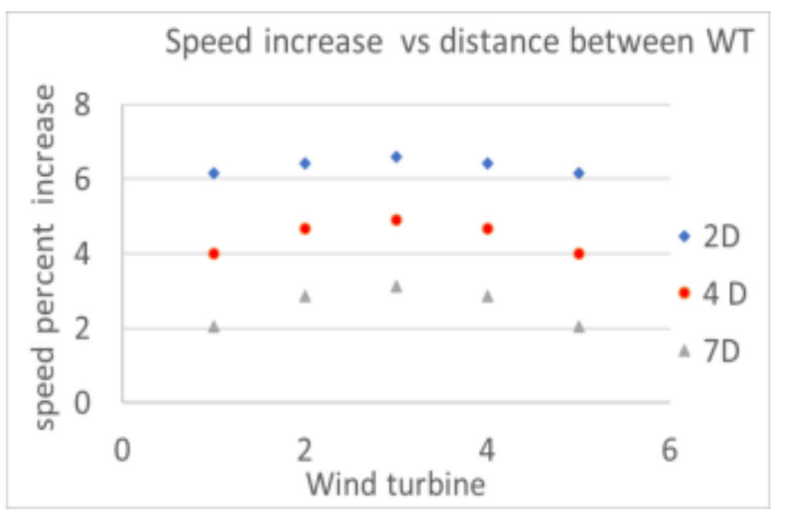

Figure 18. Five turbines with a distance varying among two, four, and seven wind turbine rotor diameters. The percent of the speed increase in front of a wind turbine row compared to a row of one turbine. 
To study the influence of a wind turbine row by another row, which is located behind of it, two rows with two different arrangements were used. These arrangements are illustrated in Figure 12. As in the case of only two turbines placed one behind the other, an increase of pressure and decrease in speed are induced by the induction zone of the second row. Therefore, the second row induces a decrease of speed over the rotors of the first row. Consequently, a small decrease in power yield and an increase in strength of the induction zone of the first row are created by the row behind. The impact of this effect increases from edge to center, in concordance with the induction zone of the second row-see Figure 19. Effects of the second row on the first row have been observed experimentally by Segalini and Dahlberg [12]. They reported a velocity decrease in the first row of the wind farm due to the presence of rows behind. Schneemann et al. [15], reported a decreasing speed in the induction zone of the wind farm. The observations were done by using scanning LiDAR.

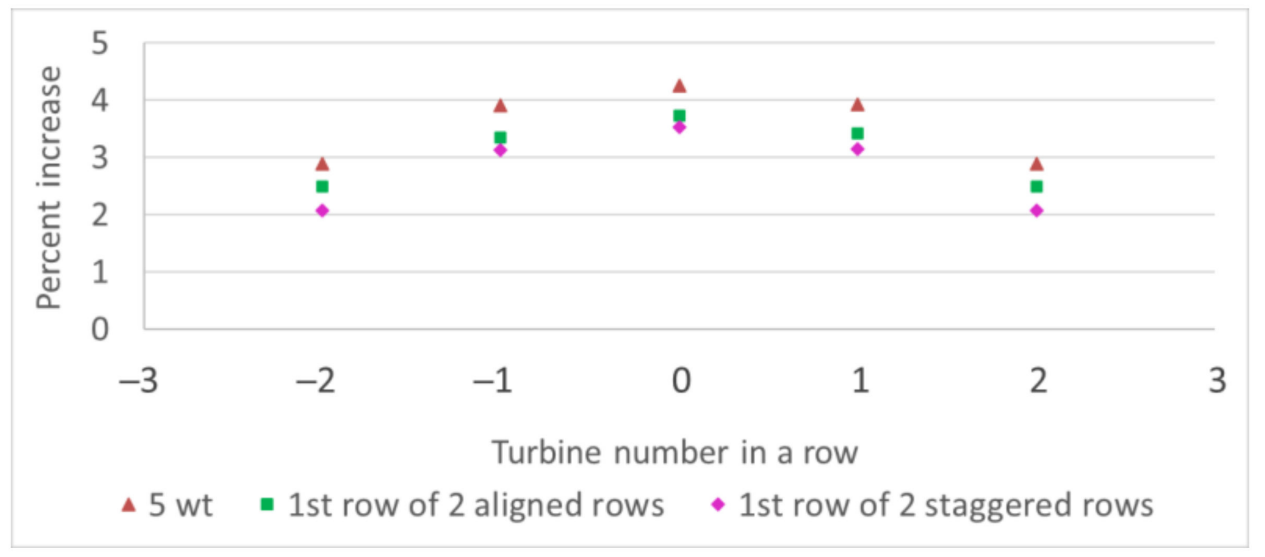

Figure 19. The speed increase in front of a wind turbine row compared to a row of one turbine. Staggered vs. aligned vs. no second row.

When the turbines were placed facing the gaps of the first row, they induce a stronger effect than one facing the turbine of the first row because: (i) they affect the edge of the first row; (ii) the second row is not in the wake; hence, they have a stronger induction zone and a stronger effect on the first row. This phenomenon could be seen in Figure 19.

\subsubsection{The Blockage Effect in a Wind Farm}

To clarify the physics of the blockage effect in a small wind farm, a 3D CFD study on a small wind farm was performed: 3 rows with 3 wind turbine each. The solver is described in Section 3. The distances between wind turbines and lines are 7 turbine diameters. Figure 20 shows that the induction zone occurs for all three rows.

The blockage effect of a row causes the wind turbine in the center of the row to have a larger power and an induction zone with larger pressure compared to the turbine situated at the end of the same row. The row induces an increase in pressure and decreases in speed for the row in front of it, accordingly with its induction zone. Consequently, the third row causes the increase of the strength of the induction zone of the second row from edge to center. The second row has a similar effect for the first row. These cumulative effects explain the strong induction zone of a wind farm. 


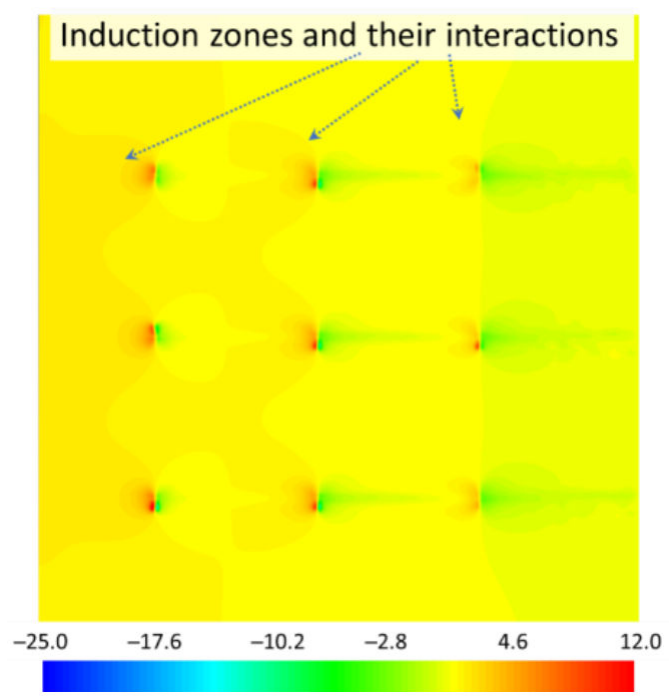

Figure 20. The induction zones and their interaction in a wind farm. A snapshot of the pressure distribution of the wind farm layout in the plane that passes through the turbine centers.

Figure 21 shows how a row is affected by two behind rows. The center turbine has a larger power than the end turbine with a $0.7 \%$ difference for the first row and $1.75 \%$ for the last row. The power ratio of the turbines of the row vs the left edge turbine of the row is lower for the first row than for the second row, and for the second row than the third row. These indicate that the power ratio of the center turbine relative to edge decreases from the last to the first row because of the accumulation of blockage effects from rows behind. This fact could induce in a large wind farm a situation where the maximum power in the first row is at the edge of the row, as was described by Segalini and Dahlberg [9]. The lowering of power of wind farms rows depends on the accumulation of blockage effect. The accumulation effects get stronger with the number of rows behind, with the number of turbines in the row, with a decreased distance between rows and with a decreased distance between turbines in a row.

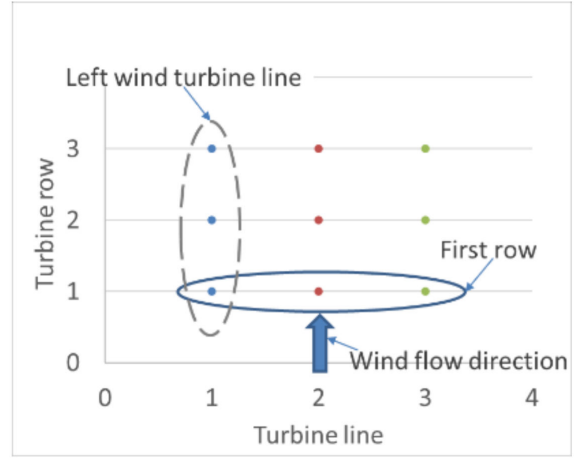

(a)

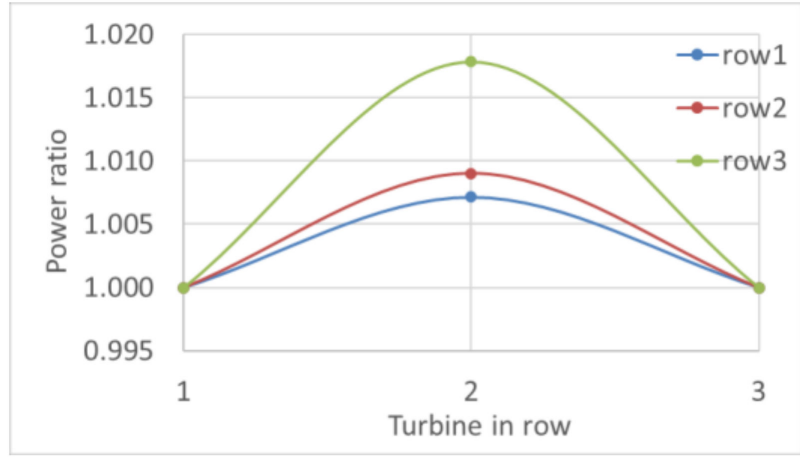

(b)

Figure 21. The blockage effect in the wind farm: (a) the details of the wind farm layout; (b) the power ratio output of turbines vs. the left edge turbine of the row.

Figure 22 indicates that each wind farm line has similar, but not identical ratios between turbine powers to the power of the free turbine of the line. This is a consequence of the same blockage effects being present in all the lines, as well as the wake being the dominant effect. 


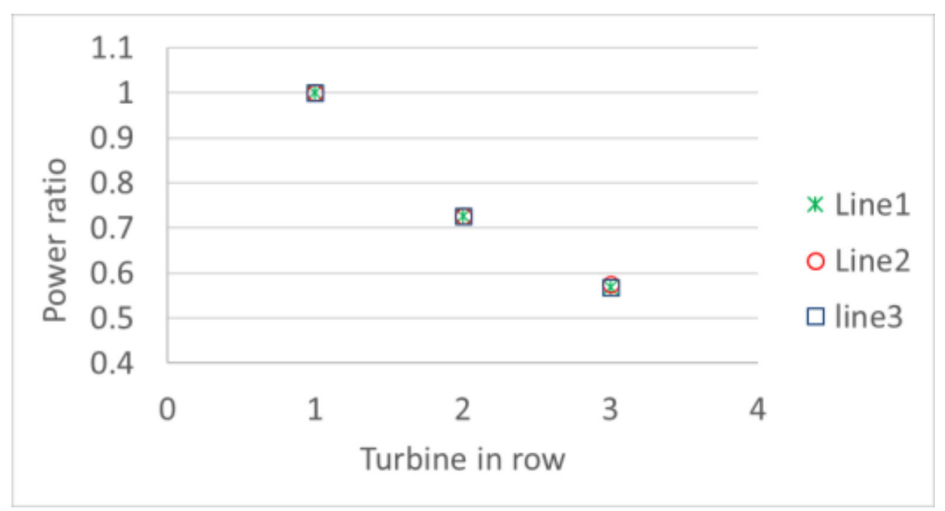

Figure 22. Power deficit in the lines: the power of each wind turbine is divided to the first turbine power in the line (turbine that is not affected by the wake).

\section{Discussions}

How the wind flow interacts with the wind turbines affects the way the turbine harvests energy from the wind. The blockage effects are the consequence of this interaction. In a wind farm, there are two important specific blockage effects: the row effect and the line effect.

The row effect is generated by the blockage effect in a row. This could be created when the row and rotors are relative perpendicular to the wind direction. The row effect induces an increase of harvested power and a stronger induction zone of a row. The strongest effect is in the middle of the row.

The line effect arises from the induction zone from rows behind. This induces a reduction in power and an increase of the strength of the induction zone. The strongest effect of the row behind is created where it has the strongest induction zone. However, the induction zone of a row is influenced by the row effect and the line effect. Consequently, the blockage effect on a turbine in a wind farm is affected by the cumulation of the row and line effect.

A wind farm blockage model that does not consider the two effects could not reproduce well the variation introduced by the presence of multiple turbines. A full engineering wind farm blockage model was proposed by Nygaard et al. [7]. The model is validated against a farm SCADA data for two directions, $80^{\circ}$ and $110^{\circ}$. The distribution of the turbine in the farm is similar to the one in Figure 23 and the studied turbines are numbered. They have a relatively good approximation for $110^{\circ}$, when all turbines are not influenced strongly by the rows behind. The least affected are turbines 1,8 , and 9 , which have the highest power. In the case of the $80^{\circ}$ wind direction, there is a stronger influence of the turbines behind, associated with a stronger decrease in power. The model seems to strongly underestimate the blockage effect.

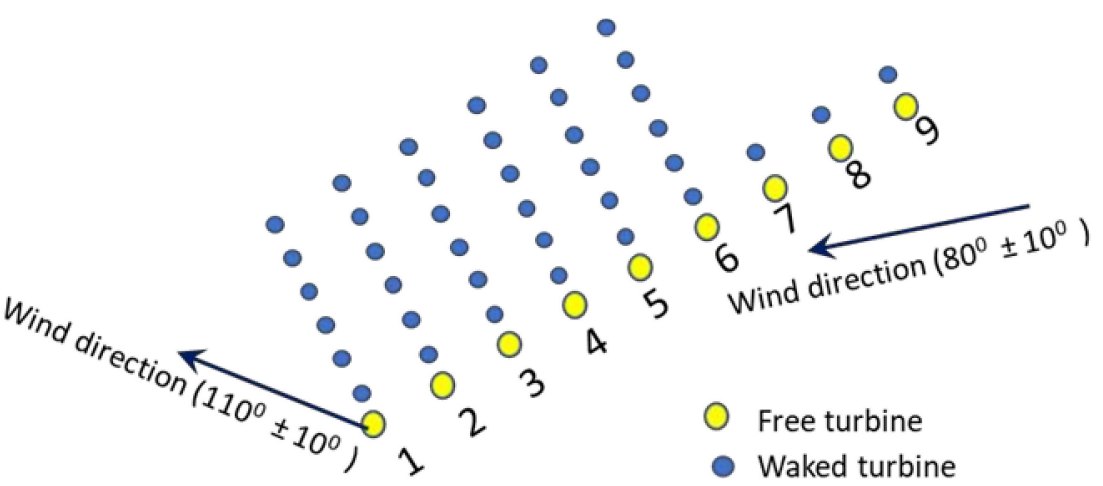

Figure 23. The wind farm. 
Segalini 6 indicated that, for the first row, the maximum power was for the turbine on the edges. However, for an isolated row, this maximum was instead observed for the turbines located in the center. This apparent strange behavior is well justified by the presence of the two concurrent phenomena: the row effect and the line effect. In an isolated row, the maximum power is produced by the turbine situated in the middle of the row because of the row effect. However, in the first row of the wind farm, there are both line and row effects. The rows behind induce the strongest decrease in power in the middle of the first row. This could cause the wind turbines on the edges of the first row to have the largest power.

\section{Conclusions}

The current work highlighted the physics behind blockage effects created by both a single turbine and turbines from an entire wind farm. The physics was revealed by $2 \mathrm{D}$ and $3 \mathrm{D}$ computational fluid dynamics simulations. The existence of the observed phenomena was verified by experiments and other CFD computations that were found in the literature.

The principles behind the blockage effects created by a single turbine or wind farm turbines are the balance between the local energy conservation, mass, and momentum conservation, and the forces that influence the performance of the wind turbine: the thrust, torque on the rotor and the kinetic energy of the incoming flow.

The principal blockage effects created by a turbine are the induction zone, the wake, the expansion flow, and associated flow increase. These are called local blockage effects.

The specific wind farm blockage effect is the direct consequence of the interaction between local blockage effects. Besides the local blockage effect, each turbine will be subject to the two important blockage effects in the wind farm:

- The row effect, which induces the power yield of the turbines in the row to be larger than for one turbine in isolation. The phenomenon also creates a stronger induction zone. The increase of the power and strength of the induction zone depends on the number of the turbine in the row and distance between them. The strongest row effect is created somewhere in the middle of the row. The exact place of the maximum effect depends on the turbine distribution in the row.

- The effect between rows:

$0 \quad$ The wake effect, which induces a drop in wind energy to the downstream flow. Consequently, the effect causes a reduction of harvested power by the turbines of rows behind.

- The line effect gives a power reduction and an increase of the strength of the induction zone of a row. The phenomenon is a consequence of the induction zone of the row behind, which induces an increase of the pressure and a reduction of the kinetic energy available. The strongest effect on a row is created where the induction zone of the row behind is strongest. Hence the negative effect of turbines behind a row depends on their spatial distribution.

An important insight of this work is that the cumulative influence of the line effect and the row effect are the essential blockage effects in a wind farm. The induction zone and the associated change in harvested power are affected by these effects. The way in which blockage effects modify the energy yield of a wind turbine depend on its position in the farm and the wind farm layout. For a row, the blockage effects influence the energy yield depending on its turbine distribution, its position in the wind farm and the farm layout.

In a wind farm, the accumulation effect of the rows behind can induce a situation where the maximum power in the wind farm first row is at the edge of the row. This is opposite from a wind turbine row situated in isolation when the maximum power is in the center of the row.

In long wind turbine lines situated behind each other, it was noticed that the power harvested by turbines situated in the wake could only have a small variation. This phenomenon is the consequence of the blockage effect interaction, which maintains a small variation of kinetic energy available for wind turbines in the wake. 
The blockage effect magnitude of each turbine of the wind farm depends on the wind farm layout, turbine type, turbulence intensity, and atmospheric stability condition [28]. Future works could target a more qualitative evaluation of these factors. Such knowledge could be used for generating engineering models that describe the blockage effect with better accuracy.

Author Contributions: Conceptualization, M.P.; methodology, M.P.; software, N/A; validation, T.F.; formal analysis, M.P.; investigation, M.P.; resources, M.P.; data curation, N/A; writing—original draft preparation, M.P. and T.F.; writing — review and editing, M.P. and T.F.; visualization, T.F.; supervision, T.F.; project administration, M.P.; funding acquisition, N/A. All authors have read and agreed to the published version of the manuscript.

Funding: This research received no external funding.

Institutional Review Board Statement: Not applicable.

Informed Consent Statement: Not applicable.

Data Availability Statement: Not applicable.

Conflicts of Interest: The authors declare no conflict of interest.

\section{References}

1. Prakash, G.; Anuta, H. Future of wind: Deployment, investment, technology, grid integration and socio-economic aspects-A Global Energy Transformation paper. Int. Reneww. Energy Agency 2019. Available online: https://www.irena.org/-/media/Files/ IRENA/Agency/Publication/2019/Oct/IRENA_Future_of_wind_2019.pdf (accessed on 6 February 2021).

2. Fraile, D.; Vandenberghe, A.; Klonari, V.; Ramirez, L.; Pineda, I.; Tardieu, P.; Malvault, B.; Komusanac, I. Getting Fit for 55 and Set for 2050 Electrifying Europe with Wind Energy. ETIPWind-WindEurope Report. June 2021. Available online: https:/ / etipwind. eu/files/reports/Flagship/fit-for-55/ETIPWind-Flagship-report-Fit-for-55-set-for-2050.pdf (accessed on 28 July 2021).

3. Churchfield, M.J. A Review of Wind Turbine Wake Models and Future Directions. In 2013 North American Wind Energy Academy (NAWEA) Symposium; National Renewable Energy Laboratory: Boulder, CO, USA, 2013.

4. Garrad Hassan and Partners Ltd. DNV-GLEnergy, Theory Manual WindFarmer, DNV-GLEnergy; Version 5.3; Garrad Hassan and Partners Ltd.: Bristol, UK, 2014; pp. 12-15.

5. Branlard, E.; Quon, E.; Forsting, A.R.M.; King, J.; Moriarty, P. Wind farm blockage effects: Comparison of different engineering models. J. Phys. Conf. Ser. 2020, 1618, 062036. [CrossRef]

6. Segalini, A. An analytical model of wind-farm blockage. J. Renew. Sustain. Energy 2021, 13, 033307. [CrossRef]

7. Nygaard, N.G.; Steen, S.T.; Lina Poulsen, L.; Pedersen, J.G. Modelling cluster wakes and wind farm blockage. J. Phys. Conf. Ser. 2020, 1618, 062072. [CrossRef]

8. McTavish, S.; Rodrigue, S.; Feszty, D.; Nitzsche, F. An investigation of in-field blockage effects in closely spaced lateral wind farm configurations: An investigation of in-field blockage effects in closely spaced lateral wind farm configurations. Wind. Energy 2015, 18, 1989-2001. [CrossRef]

9. Nishino, T.; Draper, S. Local blockage effect for wind turbines. J. Phys. Conf. Ser. 2015, 625, 012010. [CrossRef]

10. Hägglund, P.B. An Experimental Study on Global Turbine Array Effects in Large Wind Turbine Clusters. Master's Thesis, KTH Royal Institute of Technology, Stockholm, Sweden, 2013.

11. Ebenhoch, R.; Muro, B.; Dahlberg, J.-Å.; Berkesten Hägglund, P.; Segalini, A. A linearized numerical model of wind-farm flows. Wind. Energy 2017, 20, 859-875. [CrossRef]

12. Segalini, A.; Dahlberg, J.-Å. Global blockage effects in wind farms. J. Phys. Conf. Ser. 2019, 1256, 012021. [CrossRef]

13. Meyer Forsting, A.R. Modelling Wind Turbine Inflow: The Induction Zone. Ph.D. Thesis, DTU Wind Energy, Campus Risø Frederiksborgvej, Roskilde, Denmark, 2017.

14. Nygard, N.G.; Hansen, S.D. Wake effects between two neighbouring wind farms. J. Phys. Conf. Ser. 2016, 753, 032020. [CrossRef]

15. Schneemann, J.; Theuer, F.; Rott, A.; Dörenkämper, M.; Kühn, M. Offshore wind farm global blockage measured with scanning lidar. Wind. Energy Sci. 2021, 6, 521-538. [CrossRef]

16. Panjwani, B.; Popescu, M.; Samseth, J.; Meese, E.; Mahmoudi, J. OffWindSolver: Wind Farm Design Tool Based on Actuator Line/Actuator Disk Concept in OpenFoam Architecture. In Proceedings of the First Symposium on OpenFOAM@in Wind Energy, Oldenburg, Germany, 20-21 March 2013; Volume 2.

17. Troldborg, N. Actuator Line Modeling of Wind Turbine Wakes. Ph.D. Thesis, Technical University of Denmark, Lyngby, Denmark, 2008.

18. Sørensen, J.N.; Shen, W.Z. Computation of Wind Turbine Wakes Using Combined Navier-Stokes/Actuator-Line Methodology. In Proceedings of the European Wind Energy Conference, Nice, France, 1-5 March 1999.

19. Sørensen, J.N.; Shen, W.Z. Numerical Modeling of Wind Turbine Wakes. J. Fluids Eng. 2002, 124, 393-399. [CrossRef] 
20. Martínez-Tossas, L.A.; Churchfield, M.J.; Leonardi, S. Large eddy simulations of the flow past wind turbines: Actuator line and disk modeling. Wind. Energy 2014, 18, 1047-1060. [CrossRef]

21. Spera, D.A. Wind Turbine Technology: Fundamental Concepts of Wind Turbine Engineering; ASME Press: New York, NY, USA, 1994.

22. Porté-Agel, F.; Bastankhah, M.; Shamsoddin, S. Wind-Turbine and Wind-Farm Flows: A Review. Bound.-Layer Meteorol. 2019, 174, 1-59. [CrossRef] [PubMed]

23. Simley, E.; Angelou, N.; Mikkelsen, T.; Sjöholm, M.; Mann, J.; Pao, L.Y. Characterization of wind velocities in the upstream induction zone of a wind turbine using scanning continuous-wave lidars. J. Renew. Sustain. Energy 2016, 8, 013301. [CrossRef]

24. Branlard, E. Far-Wake Analyses and the Rigid Helical Wake. In Wind Turbine Aerodynamics and Vorticity-Based Methods; Research Topics in Wind Energy; Springer: Cham, Switzerland, 2017; Volume 7, Chapter 24; pp. 273-283. [CrossRef]

25. Bleeg, J.; Purcell, M.; Ruisi, R.; Traiger, E. Wind Farm Blockage and the consequences of Neglecting Its Impact on Energy Production. Energies 2018, 11, 1609. [CrossRef]

26. Nishino, T.; Draper, S. Theoretical Prediction of the Efficiency of Very Large Turbine Arrays: Combined Effects of Local Blockage and Wake Mixing. In Proceedings of the 7th Oxford Tidal Energy Workshop, Oxford, UK, 8-9 April 2019.

27. Forsting, A.R.M.; Troldborg, N. The effect of blockage on power production for laterally aligned wind turbines. J. Phys. Conf. Ser. 2015, 625, 012029. [CrossRef]

28. Montavon, C.; Bleeg, J.; Riechert, J.; Steger, M.; Soderberg, S.; Shmitt, C. Measuring and Modelling Wind-Farm-Scale Blockage Offshore-What Are the Challenges? WindEurope, Resource Assessment \& Analysis of Operating Wind Farms 2021. 8-10 September 2021. Available online: https:/ /app.swapcard.com/event/technology-workshop-2021/planning/UGxhbm5 pbmdfNTgxNzA1 (accessed on 9 September 2021). 